\title{
Knowledge and Attitude of Medical Students toward Plastic Surgery
}

\author{
Mukami Gathariki ${ }^{1}$ Martin Ajujo ${ }^{1} \quad$ Lucianne Odiero ${ }^{2} \quad$ Thomas Amuti, \\ ${ }^{1}$ Department of Plastic Surgery, University of Nairobi, \\ Nairobi, Kenya \\ 2University of Nairobi, Nairobi, Kenya \\ ${ }^{3}$ Department of Human Anatomy, University of Nairobi, \\ Nairobi, Kenya \\ J Health Allied Sci ${ }^{\mathrm{N}}: 2020 ; 10: 97-101$

\begin{abstract}
Address for correspondence Thomas Amuti, BSc, Department of Human Anatomy, University of Nairobi, Nairobi, PO Box 30197-00100, Kenya (e-mail: tomamuti@gmail.com).
\end{abstract}

\begin{abstract}
Introduction Inadequate professional and medical exposure and misconceptions about plastic surgery have not only been linked to students' poor knowledge and attitude toward it, but also bias against the selection of plastic surgery as a specialty. This assertion is yet to be tested and confirmed in our setting. This study therefore aimed to determine the knowledge and attitude of medical students toward plastic surgery. Methods One hundred and eight (108) students between their 3rd and 4th year of study were randomly recruited and handed structured questionnaires on knowledge and attitude toward plastic surgery. Data were then analyzed using SPSS and represented in percentages, medians, and means. Mann-Whitney and Kruskal-Wallis tests were done to assess for significant statistical differences based on gender grouping and year of study, respectively. A $p$-value $\leq 0.05$ was considered significant at a 95\% confidence interval.

Results Majority of the students had some awareness about plastic surgery since, a majority (88\%) identified plastic surgery with cosmetics and identified trauma as the main condition handled by plastic surgeons. Sixty-four percent (64\%) acknowledged the risks associated with plastic surgery and $79.6 \%$ noted the presence of the procedures in Kenya. When assessing attitude, 62\% reported that they did not want to pursue plastic surgery in the future, $75 \%$ would not consider plastic surgery done on them and $77 \%$ of the respondents felt embarrassed to undergo the surgery if their family knew while another $77 \%$ felt embarrassed if their friends knew. It is worth noting that $55 \%$ had their initial exposure to plastic surgery through information from the media sources. Mann-Whitney test done to assess for gender differences only revealed significant difference ( $p$-value $=0.009$ ) on assessing for the availability of plastic sur-

Keywords

- plastic surgery

- cosmetics

- medical students gery procedures in Kenya. Kruskal-Wallis test did not reveal any significant differences based on year of study.

Conclusion Data from our study suggest that students have some awareness about plastic surgery but have a poor attitude toward it.
\end{abstract}

\section{Introduction}

Plastic surgery is concerned with the treatment of deformities of the skin and subcutaneous tissues in an attempt to improve functionality and appearance. ${ }^{1}$ It is often thought
DOI https://doi.org/

$10.1055 / \mathrm{s}-0040-1715982$

ISSN 2582-4287. to consist only of its cosmetic aspect, dealing only with improvement of appearance. ${ }^{2}$ It, however, comprises multiple subspecialties such as breast surgeries, cleft lip surgery, hand surgery, maxillofacial trauma, burns, mammoplasty, abdominoplasty, liposuction among others. ${ }^{2}$ In spite of this 
diversity, several studies across different continents have shown that it is still poorly understood by many, including primary care physicians and medical students. ${ }^{2-7}$ From these studies, a dearth in knowledge surrounding plastic surgery and particularly a mixed attitude toward its practice has been reported.

Pertaining to the knowledge surrounding plastic surgery, many of the students failed in differentiating cosmetic surgery from plastic surgery. There was also a paucity of information on the subspecialties of plastic surgery as well as procedures and conditions treated by plastic surgeons. Further, in a study done in Nigeria, most of the students were not aware of the institutions practicing plastic surgery in their locale. ${ }^{7}$

With regard to their attitude, a study done on medical students in Saudi Arabia revealed that most of them did not consider plastic surgery as a prospective field they would venture in. ${ }^{8}$ They, however, reported that they would avail themselves for the procedure if need be. It is plausible that most of the students in the studies had prior knowledge but poor attitude toward plastic surgery. This may be due to their source of information and inadequate professional/medical exposure to plastic surgery.

Studies have shown that most students derive their information on plastic surgery from friends, television shows, and the internet. Very few derive their information from hospitals or doctors themselves. ${ }^{79}$ Conyard et al revealed that exposure of medical students to plastic surgery by medical professionals increased their scope of the practice and vice versa. As a result, poor knowledge and attitude could be attributed to either inadequate professional exposure or inaccurate information from media sources. ${ }^{?}$

Awareness of plastic and reconstructive surgery by medical students has multiple implications. First, the lack of awareness has repercussions for both future surgical and nonsurgical trainees who usually form a significant referral base for practicing plastic surgeons and plastic surgery as a field. This may result in a biased exposure of medical students to inaccurate information than from the professionals. ${ }^{9}$ Second, an improved understanding of plastic surgery would expedite the referral process for patients in need of the services of plastic surgery, reducing the psychological and financial costs to both patients and the health care system. ${ }^{8-10}$ Increasing the exposure to accurate information from the professionals could therefore have significant impact for both the future of the field and the local residents.

Due to scanty data and elusive medical reports, it is not known if the same issue is reflected in Kenyan setting. This study therefore sought to find out the knowledge and attitude of Kenyan medical students toward plastic surgery.

\section{Materials and Methods}

The study was a cross-sectional study that randomly recruited 108 medical students in their 2nd to 4th year of study at the University of Nairobi, Kenya. The sample size was arrived using the formula suggested by Charan and Biswas ${ }^{11}$ :

$$
n=z^{2} P(1 P) / d^{2},
$$

where $n$ is sample size, $z$ is the standard normal variate (taken as 1.96 at $95 \%$ confidence interval) and $P$ is the expected proportion of interest in a population. The variable used was "where the students got this information from" and we aimed to see how many got it from the appropriate sources. Almeland et al, ${ }^{12}$ showed that $8 \%$ of medics got their information from textbooks, thus the value of $P$ (proportion) was taken as 0.08 and $d$ is the effect size (taken as 0.05 ). With these values, a sample size ( $n$ ) of 108 was arrived after calculation.

The 2nd and 3rd years were chosen since they had not yet been introduced to plastic surgery which is done in the 4th year of medical school, at the University of Nairobi. The difference between the years would, therefore, serve as a good opportunity to assess whether professional/medical exposure to plastic surgery influences attitude toward the field. The senior years, 5th and 6th-year medical students were not included in the study since at the time of the study, they were taking their final examinations.

Prior to the administration of the questionnaires, ethical consideration was sought from the Kenyatta National Hospital and University of Nairobi Ethics and Standards Committee as well as the Dean, School of Medicine, University of Nairobi.

Prior to any data collection, both verbal and written consent was sought from the participants following which they filled the structured questionnaire. The questionnaire was structured from previously mentioned studies to maintain consistency and hence validity ( - Supplementary Material, available in the online version). The initial part of the questionnaire asked about the age, sex, race, and year of study of the respondent. In assessing their knowledge, the following questions were asked: "define cosmetic surgery," "list conditions treated by plastic surgeons," "list operations/procedures performed by plastic surgeons," "from where did you learn about plastic surgery," "list any risks associated with plastic surgery," "are you aware of plastic surgery is being conducted in your locale." In assessing their attitude, the following questions were asked: "would you like to be a plastic surgeon," "would you consider having a plastic surgery," "would you be embarrassed if your immediate family," "would you be embarrassed if your close friends knew you underwent plastic surgery."

Data collected were coded into SPSS (version 21. IBM) and presented in percentages, means, and standard deviations. Mann-Whitney test was done to assess for gender differences and Kruskal-Wallis test for assessing the statistically significant difference between the year of study and the questions. For the different questions asked, the respective findings were presented in tables.

\section{Results}

Out of 108 respondents, 48 were male and 60 were female. One hundred (93\%) of them were between 18 and 24 years and eight (7\%) were above 24 years. Twenty-eight $(26 \%)$ of 
the respondents were in their fourth year of study, 52 (48\%) were in their third, and 28 (26\%) were in their second year (-Table 1). Majority (96\%) were Africans (Kenyans), while 4\% were from the Asian community.

\section{Knowledge}

When assessed on their definition of plastic surgery, most of the respondents (95 out of 108) 88\% described it as surgery that is done to improve appearance. Three out of 108 (3\%) defined it as corrective surgery, (2 out of 108) $2 \%$ as reconstructive surgery, ( 1 out of 108 ) 1\% as repair of tissues, ( 1 out of 108$) 1 \%$ as beautification, (1 out of 108) $2 \%$ as reconstructive surgery, and (1 out of 108) $1 \%$ as the placing of implants. There were no significant differences on the responses given based on the gender or year of study ( - Table 2 )

The respondents were also assessed on the conditions that are handled by plastic surgeons. Trauma was identified as the main condition (68 respondents) followed by cleft lip (25 respondents), cleft palate (16 respondents), and finally scars (nine respondents). Liposuction was the most common procedure (49 respondents), followed by breast enhancement (46 respondents) and rhinoplasty (24 respondents). Overall, most students suggested four to six procedures irrespective of the year of study. There were no significant differences on the responses given based on the gender or year of study (-Table 2).

Sixty-four percent of the respondents noted that there were risks identified with plastic surgery whereas $34 \%$ did not. The remaining $2 \%$ were not sure as to whether there were any risks involved. The most common risk noted was

Table 1 Table showing the distribution of responses per year of study $(N=108)$

\begin{tabular}{|l|l|}
\hline Year of study & Number of participants \\
\hline 4th year of study & 28 \\
\hline 3rd year of study & 52 \\
\hline 2nd year of study & 28 \\
\hline
\end{tabular}

infections (39 respondents), death (17 respondents), and rejection (11 respondents). There were no significant differences on the responses given based on the gender or year of study (-Table 2).

On the availability of the procedures in Kenya, 86 out of 108 respondents $(79.6 \%)$ noted that it was available whereas $22(20.4 \%)$ noted that it was not available. There was, however, a significant difference based on gender on the awareness ( $p$-value $=0.009$ ) with female students being more aware than the males following Mann-Whitney test but no differences noted based on the year of study (-Table 2 ).

With regard to initial exposure to plastic surgery-related content, 55\% noted that they heard it from the television, $19 \%$ from the internet, $12 \%$ from school, $11 \%$ from social media, and $3 \%$ from friends.

\section{Attitude}

The respondents were then asked if they would want to pursue plastic surgery in their future practice. Sixty-two percent of the respondents reported that they did not, 37\% agreed that they would whereas $1 \%$ were not sure. When assessed if they would consider a plastic surgery being done on them at the moment of answering the questionnaire, majority (75\%) denied. The majority of the respondents (52\%) also refused to undergo surgery in the near future. There were no statistically significant differences based on the gender or the year of study (-Table 2).

When assessed on the factors that would influence their choice of undergoing surgery, such as the influence of family and friends, $77 \%$ of the respondents reported feeling embarrassed to undergo the surgery if their family knew. Seventyseven percent $(77 \%)$ also reported feeling embarrassed if their friends knew. There was no statistically significant difference based on the gender or the year of study ( - Table 2 ).

\section{Discussion}

Data from our study tend to suggest that medical students have some awareness of plastic surgery but a poor attitude to the same. Similar studies done in different populations

Table 2 Table showing the results of Mann Whitney and Kruskal-Wallis tests $(N=108)$

\begin{tabular}{|l|l|l|}
\hline Question & $\begin{array}{l}\text { Mann Whitney test ( } p \text {-value): } \\
\text { assessing gender differences }\end{array}$ & $\begin{array}{l}\text { Kruskal-Wallis test ( } p \text {-value): } \\
\text { assessing difference based } \\
\text { on year of study }\end{array}$ \\
\hline Define plastic surgery & 0.445 & 0.325 \\
\hline What are the conditions assessed by plastic surgeons? & 0.114 & 0.425 \\
\hline What are the risks associated with plastic surgery? & 0.231 & 0.665 \\
\hline Are you aware of plastic surgery centers in Kenya? & 0.009 & 0.995 \\
\hline Would you want to be a plastic surgeon? & 0.128 & 0.157 \\
\hline Do you know any risks associated with plastic surgery? & 0.439 & 1.743 \\
\hline Would you consider having a plastic surgery? & 0.238 & 1.623 \\
\hline $\begin{array}{l}\text { Would you be embarrassed about undergoing a plastic } \\
\text { surgery if your immediate family knew? }\end{array}$ & 0.242 & 0.420 \\
\hline $\begin{array}{l}\text { Would you be embarrassed about undergoing a plastic } \\
\text { surgery if your close friends knew? }\end{array}$ & 0.154 & 0.315 \\
\hline
\end{tabular}


especially those in the developing world tend to support this. $2,8,9,13$

\section{Knowledge}

From our findings, the majority of the students identified plastic surgery with cosmetics with many describing it as a surgery meant to improve appearance. Similar findings were noted among the health care professionals in India (80\%) who thought it principally served cosmetic purposes. ${ }^{13}$ When further asked about the conditions handled in plastic surgery, many of the students cited trauma, cleft lip, cleft palate, and scars as the main conditions. Our findings were different from that of a study done in Saudi Arabia where the most common conditions noted were burns, lifting and tightening of the face, breast reconstructions and wound management. ${ }^{9}$ In the Indian populace, burns were mostly noted to be handled by plastic surgeons (20.4\%) as well as ulcers and cleft lip/palate. Even though most students could easily mention some of the conditions and procedures handled by plastic surgeons, their knowledge on the same was limited. ${ }^{13}$ This may be due to poor exposures of plastic surgery in the respective populations.

Findings from our study also showed that the common procedures thought to be done by plastic surgeons included liposuction (41\%), breast enhancement (37\%), and rhinoplasty (21\%). In a comparative Nigerian study, the conditions handled by plastic surgeons were noted to be: removal of tattoos, breast augmentation/reconstructions, facelift, Botox and rhinoplasty. ${ }^{7}$ Further, in India, the conditions that were majorly noted to be handled by plastic surgeons were hypospadias, liposuction, breast augmentation or reduction, hair grafting, and rhinoplasty. In Saudi Arabia, rhinoplasty, breast enhancements, and blepharoplasty were noted. ${ }^{9}$ In Canada, students reported that plastic surgeons mostly perform hair transplant surgery (89.9\%), facial scar surgery $(88.0 \%)$, and rhinoplasty $(83.4 \%) .{ }^{10}$ In the Nigerian population, ${ }^{14}$ the most common procedures were liposuction $(88.2 \%)$ and hair transplant surgery $(84.4 \%)$; in contrast, liposuction was named by only $53 \%$ of our study participants. The differences noted in the procedures being performed by plastic surgeons may be due to the different levels of professional/medical exposures on plastic surgery to the different populations.

Majority of the students agreed that in deed there were risks associated with plastic surgery, with the major ones being infection and death. Similarly, a study done in India was in support that plastic surgery bore risks. ${ }^{13}$ Their analysis, however, was not specified.

Majority of the respondents reported demonstrated awareness of the availability of plastic surgery procedures in our setting. Our findings are different from that of Isiguzo et $\mathrm{al}^{7}$ who reported a minority demonstrating such awareness among the Nigerian population. Furthermore, female participants were noted to be aware of plastic surgery services than males. This may be because, in our setting, most of the exposure may be from inaccurate sources leading to a biased tendency for females to seek corrective surgery compared with males.

\section{Attitude}

Data from our findings showed that most students would not want to pursue plastic surgery in the future. Our findings were similar to separate studies done in Saudi Arabia where in one sample $38.8 \%$ of the students wanted to pursue plastic surgery, while in another, only $11 \%{ }^{8,9}$ There was no gender or year related difference noted.

Also, majority of the students in our setting displayed unwillingness to undergo plastic surgery. Our findings were different from those by Isiguzo et $\mathrm{al}^{7}$ where most of the students in the Nigerian population were willing to undergo plastic surgery if presented with the option. The difference may be due to the influence of culture as well as the family and friends. In our setting, $77 \%$ of the respondents reported feeling embarrassed to undergo the surgery if their family knew and $77 \%$ also reported feeling embarrassed if their friends knew. The role of family and friends as noted then may explain the difference in the willingness to undergo plastic surgery as seen between our setting and that of Nigeria. ${ }^{7}$

It is worth noting that in our setting, most students reported hearing of plastic surgery from the television (55\%) and the internet (19\%). This was similar to Isiguzo's study where the internet (15.7\%), friends (15.7\%), and television (14.8\%) were noted to be the main source of their information. ${ }^{7}$ Easy access to television and internet devices in our age and era may explain the reason why most of the students get their information from these sources. Most satellite TV packages, films, and media available today have stations devoted to aesthetic plastic surgery ${ }^{15-18}$ and as a result, may act as a source of information for the students. The difference noted in the sources of information might arise due to the availability of the television and internet in the area of students' study. Studies done have shown that professional/medical exposure to plastic surgery improves students' knowledge of the scope of practice and may influence their knowledge and attitude of the same., ${ }^{79}$ Therefore, more efforts should be made toward promoting this professional/medical exposure. Further, information passed through the internet and television should be verified to ensure that the right information is being passed.

\section{Limitations}

In this study, we assessed students strictly from the University of Nairobi who might have different exposures as compared with those from other settings. Similarly, the university is located in an urban setting, and this might have biased the results (on matters such as awareness of plastic surgery facilities). We therefore plan to conduct similar studies in other universities in both urban and rural setting and hopefully compare the results to assess the effects brought about by being in different universities.

\section{Conclusion}

The students in our setting had some awareness about plastic surgery but had a poor attitude toward it. Increased 
professional outreaches and professional/medical exposure are therefore advised.

\section{Conflict of Interest}

None declared.

\section{Acknowledgments}

We would like to sincerely thank the Dean, School of Medicine, for granting us the permission to carry out the study as well as the students who participated in the study.

\section{References}

1 Panse N, Panse S, Kulkarni P, Dhongde R, Sahasrabudhe P. Awareness and perception of plastic surgery among healthcare professionals in Pune, India: do they really know what we do? Plast Surg Int 2012;2012:962169

2 Conyard C, Schaefer N, Williams D, Beem H, McDougall J. The understanding of plastic and reconstructive surgery amongst Queensland medical students. JPRAS Open 2016;8:14-18

3 Akpuaka FC, Stretching Plastic Surgery to the Horizon in Africa. Inaugural Lecture Series 3. Uturu: Abia State University; 1999

4 Adigun IA, Oluwatosin OM. Knowledge of the scope of plastic and reconstructive surgery by surgical specialists at Ibadan and Ilorin, Nigeria. Niger J Med 2003;12(2):91-93

5 Pawan A. Perception of plastic surgery in the society. Indian J Plast Surg 2004;37(2):110-114

6 Chukwuanukw TO. Plastic surgery in Nigeria: scope and challenges. Niger J Surg 2011;17:68-72

7 Isiguzo CM, Nwachukwu CD. Knowledge and perception of plastic surgery among tertiary education students in Enugu, South-East Nigeria. Niger J Clin Pract 2016;19(3):327-331
8 Fayi KA, Al-Sharif MN, Alobaidi AA, Alqarni MA, Alghamdi $\mathrm{MH}$, Alqahatani BA. Male medical students' perception of plastic surgery and its relationship with their cultural factors. J Family Med Prim Care 2018;7(6):1482-1487

9 Mortada HH, Alqahtani YA, Seraj HZ, Albishi WK, Aljaaly HA. Perception of plastic surgery and the role of media among medical students: cross-sectional study. Interact J Med Res 2019;8(2):e12999

10 Fraser SJ, Al Youha S, Rasmussen PJ, Williams JG. Medical student perception of plastic surgery and the impact of mainstream media. Plast Surg (Oakv) 2017;25(1):48-53

11 Charan J, Biswas T. How to calculate sample size for different study designs in medical research. ? Indian J Psychol Med 2013;35(2):121-126

12 Almeland SK, Guttormsen AB, de Weerd L, Nordgaard HB, Freccero C, Hansson E. Plastic surgery in the Norwegian undergraduate medical curriculum: students' knowledge and attitudes. A nationwide case-control study. J Plast Surg Hand Surg 2017;51(2):136-142

13 Kumar V, Singh AK, Faisal A, Nandini R. Awareness among medical fraternity regarding the role of plastic surgeon. Indian J Plast Surg 2011;44(3):494-497

14 Adeyemo WL, Mofikoya BO, Bamgbose BO. Knowledge and perceptions of facial plastic surgery among a selected group of professionals in Lagos, Nigeria. J Plast Reconstr Aesthet Surg 2010;63(4):578-582

15 Bodenham DC. Training of plastic surgeons. Br J Plast Surg 1970;23(2):97-99

16 Romm S, Goldwyn RM. Plastic surgeon in the writer's eye. Plast Reconstr Surg 1987;80(3):455-460

17 Palcheff-Wiemer M, Concannon MJ, Conn VS, Puckett CL. The impact of the media on women with breast implants. Plast Reconstr Surg 1993;92(5):779-785

18 Furnham A, Levitas J. Factors that motivate people to undergo cosmetic surgery. Can J Plast Surg 2012;20(4):e47-e50 